Wenchao Wang ${ }^{1,2, \star}$, Fashe $\mathrm{Li}^{1,2, \star}$ and Ying $\mathrm{Li}^{1}$

\title{
Kinetics and the fluidity of the stearic acid esters with different carbon backbones
}

https://doi.org/10.1515/gps-2019-0046

Received October 02, 2018; accepted May 16, 2019.

\begin{abstract}
In this work, stearic acid esters were prepared using [HPY] $\left[\mathrm{HSO}_{4}\right]$ ionic liquids as catalysts and different kinds of alcohols and stearic acid as reactants in a self-designed reactor. Catalytic esterification, kinetics analysis and low temperature fluidity of the esters were studied. Through single-factor experiment, the optimal reaction conditions were determined for methyl stearate, ethyl ester, propyl ester, butyl ester, and amyl ester. The conversion rates under the optimized conditions were all above $97 \%$. The kinetics of the reaction process of all five esters was analyzed by the integral method, and the activation energy, pre-exponential factor and kinetic model were obtained for the five esters. Finally, the low temperature fluidity of all esters was tested and the best value was observed for amyl alcohol. Therefore, these esters would be useful additives for reducing the condensation and cold filter plugging points of biodiesel, thus improving the cold flow properties of biodiesel.
\end{abstract}

Keywords: catalytic esterification; single-factor experiment kinetics; low-temperature fluidity study

\section{Introduction}

Rapid economic development has increased the consumption of petroleum products, causing energy crisis and environmental concerns. Thus, development of

\footnotetext{
* Corresponding authors: Wenchao Wang and Fashe Li, The Metallurgy and Energy Engineering of Kunming University of Science and Technology, Yunnan, Kunming, 650093 China; The State Key Laboratory for Building and Cleaning Use of Complex Non-Ferrous Metal Resources, Yunnan, Kunming, 650093 China, e-mail: 861881751@qq.com, asanli@foxmail.com; Ying Li, The Metallurgy and Energy Engineering of Kunming University of Science and Technology, Yunnan, Kunming, 650093 China
}

alternative fuels is necessary [1]. Biodiesel is a liquid fuel with many environmental and combustion advantages such as low sulfur content, high cetane number, good lubricating performance and low emissions [2-5]. However, it contains a large number of medium- and longchain methyl esters of saturated fatty acids. These esters crystallize easily in the diesel engine causing engine blockages. They also affect low-temperature fluidity of the biodiesel. Both these issues affect the normal operation of the engine [6-9]. Currently, low-temperature fluidity of biodiesel is achieved mainly by blending methods and addition of pour point depressants [10-13].

Various methods have been developed to improve the low-temperature flow performance of biodiesel. Huang et al. [14] experimentally studied the effect of pour point depressant (PPD), polyglycerol ester (PGE), and other additives on the low temperature performance of palm oil biodiesel. Cai et al. [15] reported that the blending of palm oil with diesel oil can prevent the regular growth of saturated fatty acid methyl ester crystals, making it difficult to form a three-dimensional spatial structure, thus effectively improving the low temperature fluidity of palm oil. Makarevičiené et al. [16] reported the possibility of improving the low temperature fluidity of biodiesel fuel by mixing with butanol. Ranjan et al. [17] added petrochemical diesel oil and magnesium oxide (MgO) nanoparticles to biodiesel, and found that the low temperature fluidity was better after adding $\mathrm{MgO}$ nanoparticles. Joshi et al. [18] added ethyl levulinate diluent to reduce the freezing point and cold filter point of biodiesel, improving its low temperature flow performance.

Ethanol, propyl alcohol, butanol, butanol and amyl alcohol can also be used instead of methyl alcohol to improve the low temperature performance of biodiesel. However, this area has been rarely explored. Therefore, studying the low temperature flow performance, kinetic analysis, and mechanism of biodiesel is of great strategic significance. In this study, various stearic acid ester derivatives were synthesized as additives for biodiesel and the low temperature performance of biodiesel was investigated and optimized. 


\section{Experimental}

\subsection{Materials and reagents}

Pyridine bisulfate, $1 \mathrm{~mol} / \mathrm{L}$ phenolphthalein solution, $0.1 \mathrm{~mol} / \mathrm{L} \mathrm{KOH}$-ethanol solution and ultrapure water were prepared in our laboratory. Stearic acid, methanol, ethanol, propanol, butanol, pentanol, petroleum ether, acetic acid ethyl ester, anhydrous ethanol, 95\% ethanol, potassium hydroxide, and concentrated sulfuric acid were purchased and were of analytical grade. Sulfuric acid concentration was $\geq 99.5 \%$.

\subsection{Test methods}

\subsubsection{Equipment}

The following instruments and lab equipment were used in this work: AL204 electronic balance (METTLER TOLEDO Instrument), SK5200HP ultrasonic cleaner (Shanghai Branch Ultrasonic Instrument), 602B digital temperature oil bath (Jintan Dadi Automatic Instrument Factory), R-205 rotary evaporator (Buchi, Switzerland), SYD265D kinematic viscosity tester for petroleum products (Shanghai Changji Geological Instruments), 101A-1 electric blast drying oven (Shanghai Chongming Experimental Instrument Factory), SYP1022-III SYP2007-II fractional fuel condensation point suction filter (Shanghai God Kai Petrochemical Equipment), SYD 264 acidity titration setup (Shanghai Shen Kai Petrochemical Equipment) and Nicolet 10 Fourier transform infrared spectrometer (FTIR, Thermo Fisher Scientific).

\subsubsection{Pyridine disulfate preparation}

Pyridine disulfate was prepared using the following procedure. Pyridine (3 mol) was placed in a three-neck flask in an ice bath and magnetically stirred. Concentrated sulfuric acid was added dropwise until white solid was formed. Subsequently, the white solid was dissolved in anhydrous ethanol. Then, activated carbon was added and the stirring was continued. The resulting filtrate was rotated under reduced pressure and distilled. It was then washed with petroleum ether and ethyl acetate 3 times and placed in a vacuum drying oven. After drying at $80^{\circ} \mathrm{C}$ for $6 \mathrm{~h}$ at constant temperature, it was cooled to room temperature. Reaction scheme for the pyridine bisulfate ionic liquid synthesis is shown in Figure 1.

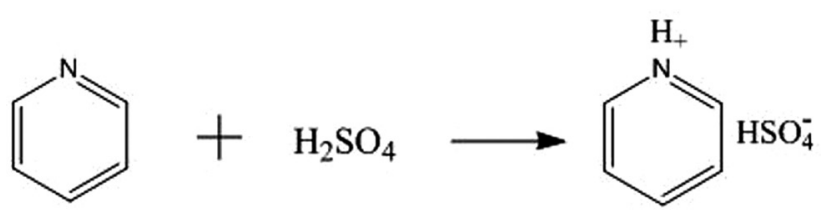

Figure 1: Chemical equation of the synthesis of pyridine bisulfate ionic liquid.

\subsubsection{Preparation of stearic acid esters}

Stearate esters were prepared using the following procedure. Stearic acid and alcohols as well as a catalyst were placed in a three-neck flask equipped with a thermometer, stirrer, and reflux condenser. The three-neck flask was placed in a water bath and heated under constant stirring. At the end of the reaction, the product was washed multiple times with ultra-pure water and placed in a rotary evaporator for vacuum distillation. Unreacted alcohols were distilled and recovered, and the reaction product was placed in a vacuum drying box for several hours.

\subsubsection{Stearic acid ester yield calculation}

Acid value of the samples was determined by classical titration using ether:ethanol solution (2:1), secondary standard aqueous solution of $\mathrm{KOH}$ with a concentration of $0.1 \mathrm{~mol} \cdot \mathrm{L}^{-1}$, previously titrated with primary standard aqueous potassium biphthalate, and alcoholic phenolphthalein solution $1.0 \%(\mathrm{w} / \mathrm{v})$ as indicator. Triplicate titration was performed with $2.0 \mathrm{~g}$ of an aliquot for each sampling point. Acid values of the initial stearic acid and synthesized stearic acid ester were analyzed. The yield of esterification reaction was calculated using Eq. 1:

$$
\text { Esterification conversion }=\frac{A V_{0}-A V}{A V} \times 100 \%
$$

where $A V_{0}$ and $\mathrm{AV}$ are the acid values of the initial raw material and the reaction product, respectively.

\subsubsection{Low temperature flow testing}

Low temperature fluidity was characterized by solidification point, cold filter plugging point and kinematic viscosity. The condensation point was measured using GB/T510-1983 method. The cold filter point was determined by SH/T0248-2006 method. Kinematic viscosity was measured by GB/T265-1988 method. 


\subsubsection{Infrared spectrum detection}

Infrared spectra were collected using an FTIR spectrometer (ALPHA, Bruker, Germany). The detection parameters were: resolution of $4 \mathrm{~cm}^{-1}$, sample scanning of 10 times, background scanning of 10 times, and wavenumber range from $100 \mathrm{~cm}^{-1}$ to $4500 \mathrm{~cm}^{-1}$. OPUS software was used for data analysis.

\section{Results and discussion}

\subsection{Catalyst recycling characteristics}

The more times the catalyst can be used, the lower its industrial cost. Therefore, the recycling characteristics of the catalyst are one of the important indicators to measure the performance of the catalyst. The ionic liquid catalyst was recovered by extracting the reaction mixture with petroleum ether and washed several times with water. The aqueous solution was collected for recovering the branched alcohol starting material. Water and alcohol were removed by concentrating the aqueous solution under reduced pressure using a rotary evaporator at $80^{\circ} \mathrm{C}$ and $95^{\circ} \mathrm{C}$, respectively. Finally, the residue was dried at $80^{\circ} \mathrm{C}$ for $5 \mathrm{~h}$ to recover the ionic liquid. The reaction time was 60 min using ionic liquid as the catalyst at $100^{\circ} \mathrm{C}$ with 5:1 molar ratio of catalyst to alkyd. The catalyst was recycled for 6 times and reused, as shown in Figure 2. It was found that the esterification rate decreased slightly with increasing number of cycles, but the catalyst still maintained high catalytic activity. The esterification rate

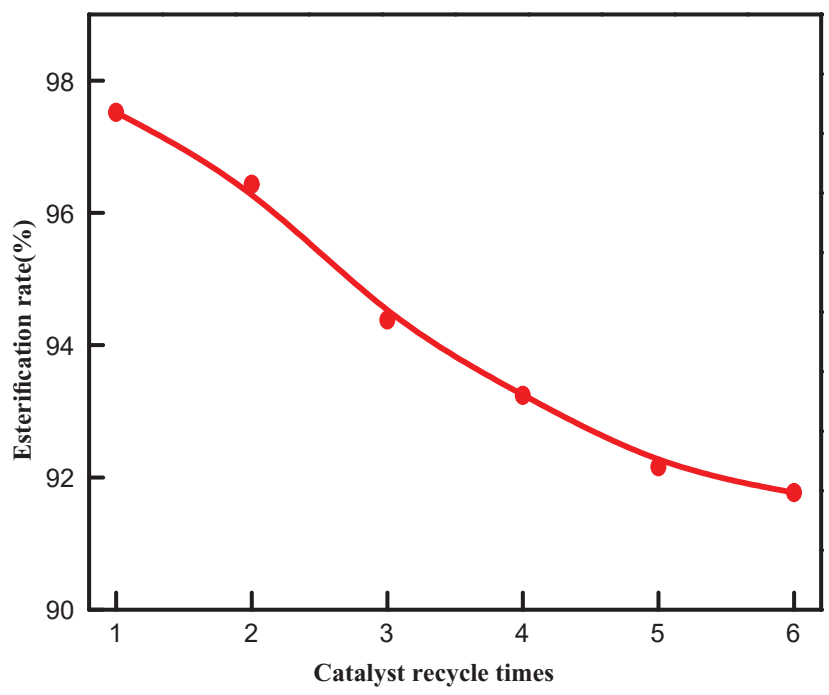

Figure 2: Effect of catalyst recycle times on esterification rate. was $90.1 \%$ after six cycles of use, showing good stability of the catalyst.

\subsection{Optimization of the esterification reaction}

The single-factor test analysis was carried for all five prepared esters. The effects of alkyd: acid molar ratio, reaction time, reaction temperature and amount of catalyst on the yield and esterification conversion rate were analyzed. The results for the methyl stearate conversion rates are shown in Figure 3.

\subsubsection{Effect of alkyd molar ratio on the esterification yield}

Esterification reactions are reversible and excess methanol can accelerate the reaction rate affecting the final yield. Effect of molar ratio of alkyd and acid on esterification reaction at $65^{\circ} \mathrm{C}$ with 90 min duration and catalyst dosage of $7 \%$ is shown in Figure 3 (blue curve). Esterification yield increased with the increase in molar ratio of alkyd: acid and reached its maximum at the ratio of 30:1, after which the yield decreased. Reactant concentrations typically increased as the alkyd: acid molar ratio increased, favoring the incraese in yield of forward reaction. However, when excess of methanol was added, the concentration of stearic acid decreased, which inhibited the esterification reaction and decreased the

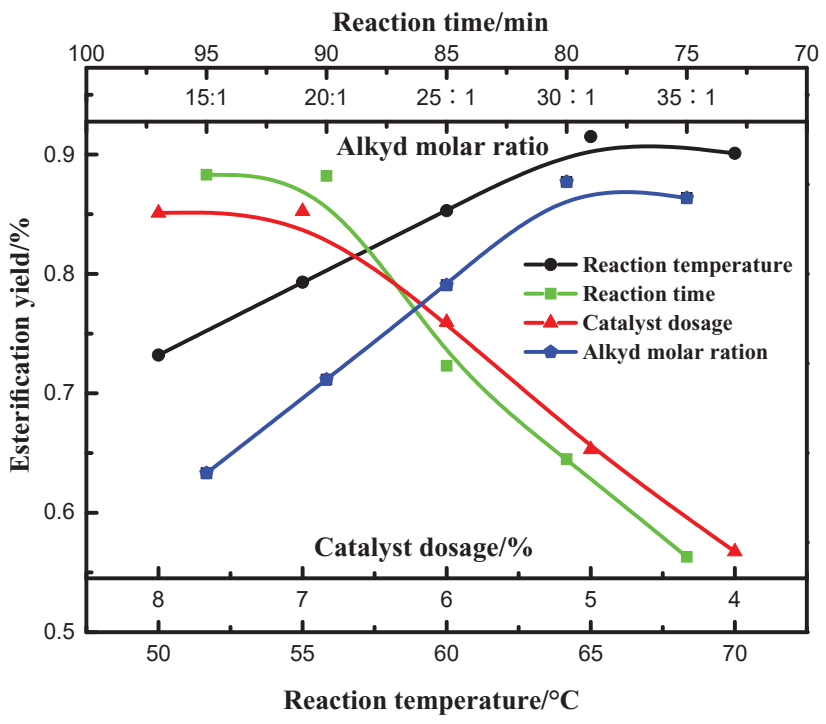

Figure 3: Effect of different factors on the conversion rate of methyl stearate. 
reaction yield. Therefore, the optimum alkyd : acid molar ratio was determined to be 30:1.

\subsubsection{Effect of reaction time on the esterification yield}

Figure 3 (green curve) also shows the effect of reaction time on the yield of esterification reaction at $65^{\circ} \mathrm{C}$, with alkyd: acid molar ratio equal to 30:1 and catalyst concentration of $7 \%$. Esterification yield increased with the increase in reaction time. At reaction time equal to $90 \mathrm{~min}$, the yield of esterification reached its maximum and then decreased with further increase in the reaction time. This is mainly because with the increase in reaction time, the concentration of products gradually increased, slowing down the forward reaction. Additionally, other side reactions occurred with the increase in reaction time, decreasing the yield of the esterification reaction. Therefore, the reaction time should be maintained at $90 \mathrm{~min}$.

\subsubsection{Catalyst concentration effect on the esterification yield}

The amount of catalyst was positively correlated with the esterification yield (see Figure 3, red curve) when the reaction conditions were set at $65^{\circ} \mathrm{C}, 90 \mathrm{~min}$ reaction time and alkyd: acid ratio equal to 30:1. However, at catalyst concentration $>7 \%$, the yield started to decrease. Presence of polar adjustable ionic liquids can increase the mutual solubility of ionic liquid, methanol and stearic acid, enhancing the esterification reaction. However, excess catalyst leads to a gradual decrease in esterification yield due to the more complex reaction mechanism and difficulty in handling the product. The presence of excess catalyst also causes a large amount of wastewater to be generated in the subsequent recovery process, which will not only waste water but also pollute the surrounding environment. Therefore, the amount of catalyst should be $7 \%$ or less.

\subsubsection{Effect of reaction temperature on the yield of esterification reaction}

The yield of esterification reaction in the early stage was positively correlated with the reaction temperature. As the temperature increased, esterification reaction yield increased as well at 90 min of total reaction time, $7 \%$ of catalyst and alkyd: acid ratio equal to 30:1. The reaction yield reached its maximum at $65^{\circ} \mathrm{C}$. At higher temperatures, the yield first stabilized and then decreased because of the lower activity of ionic liquid at higher temperatures. High temperature deactivates the ionic liquid, decreasing the yield of esterification reaction and inducing other side reactions. Therefore, the reaction temperature should be maintained at $65^{\circ} \mathrm{C}$.

Similar results were observed for ethyl stearate, propyl stearate, butyl stearate and amyl stearate (see Figure 4). The optimal preparation conditions for the five esters are shown in Table 1.

The optimal conditions for the different stearic acid esters with different backbones were different. However, all the conversion rates were above $97 \%$ at the optimum conditions.

\subsection{Analysis of the esterification kinetics}

The esterification kinetics was analyzed using integral method. Kinetics studies of elementary reactions and their rates are a part of physical chemistry field [19]. Kinetic analysis involves the study of chemical reaction rates and the conditions affecting the reaction rate as well as the relationship between structure and reactivity. It also involves study of factors that control chemical reactions. Dynamic analysis methods include differential, half-life, integral, isolation methods, etc. [20].

\subsubsection{Determination of reaction order}

Formation of stearic acid esters can be schematically presented as follows:

$$
\begin{array}{ccccc}
\mathrm{CH}_{3}\left(\mathrm{CH}_{2}\right)_{16} \mathrm{COOH}+\mathrm{ROH} \leftrightarrow \mathrm{CH}_{3}\left(\mathrm{CH}_{2}\right)_{16} \mathrm{COOR}+\mathrm{H}_{2} \mathrm{O} \\
\mathrm{t}=0 & \mathrm{C}_{\mathrm{AO}} & \mathrm{C}_{\mathrm{BO}} & 0 & 0 \\
\mathrm{t}=\mathrm{t} & \mathrm{C}_{\mathrm{A}} & \mathrm{C}_{\mathrm{B}} & \mathrm{C}_{\mathrm{C}} & \mathrm{C}_{\mathrm{D}}
\end{array}
$$

where $\mathrm{R}$ represents different alcohols, $\mathrm{C}_{\mathrm{A} 0}$ and $\mathrm{C}_{\mathrm{B} 0}$ are the initial concentrations of stearic acid and alcohol, respectively, and $C_{A}, C_{B}, C_{C}$, and $C_{D}$ are the concentrations of stearic acid, alcohol, ester and water at time t.

The kinetic equation for this reaction can be expressed as follows:

$$
r_{A}=k_{1} C_{A}^{a} C_{B}^{b}-k_{2} C_{R}^{r} C_{D}^{d}
$$

where $a$ and $b$ are the molar contents of stearic acid and alcohol; $k_{1}$ and $k_{2}$ are the reaction constants for 


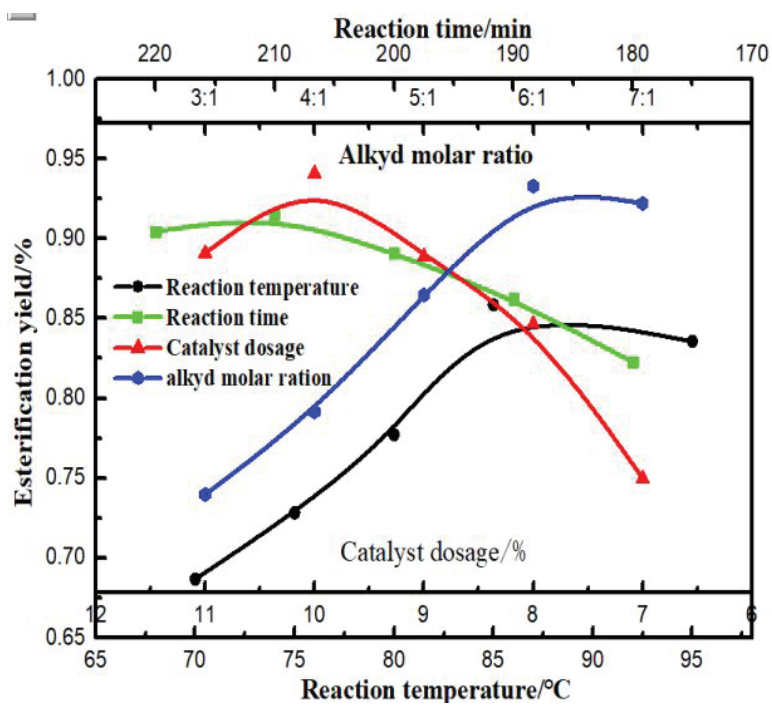

(a)

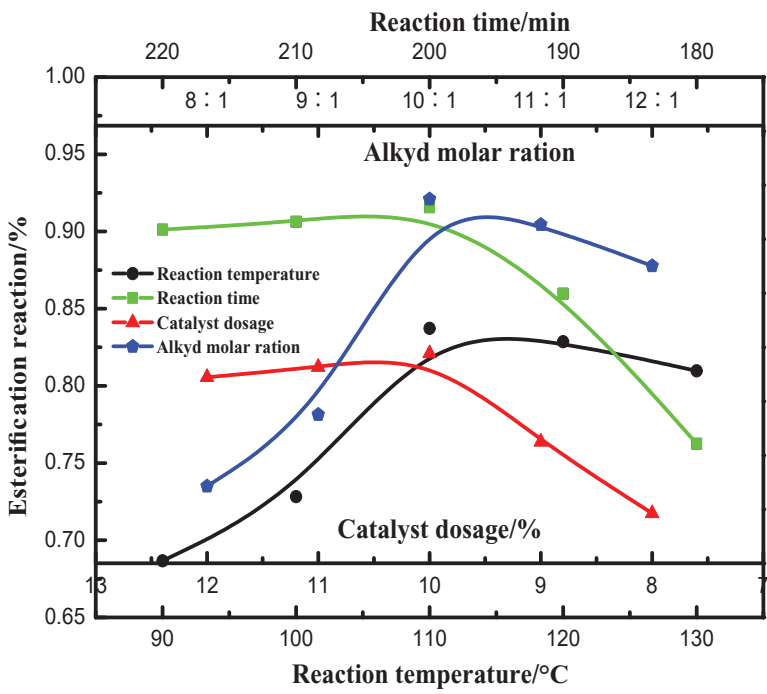

(c)

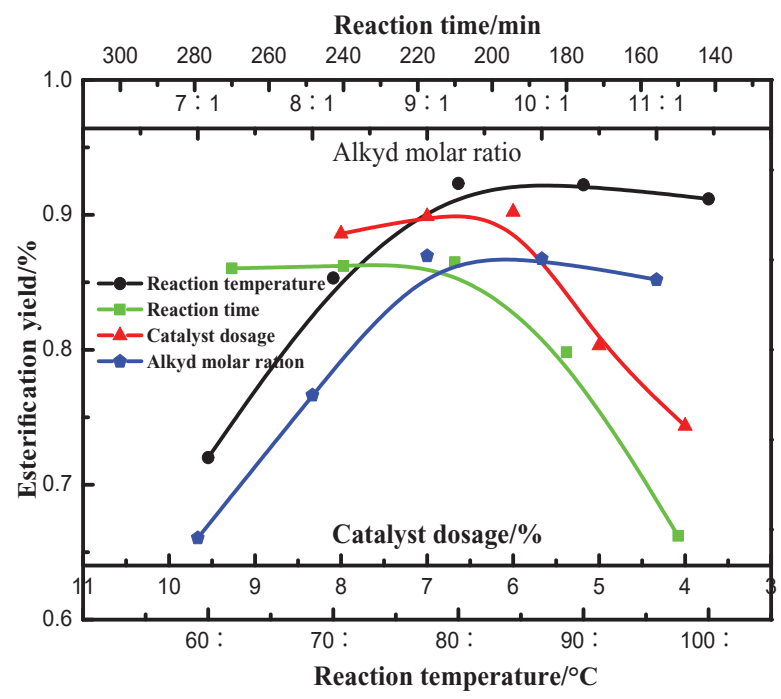

(b)

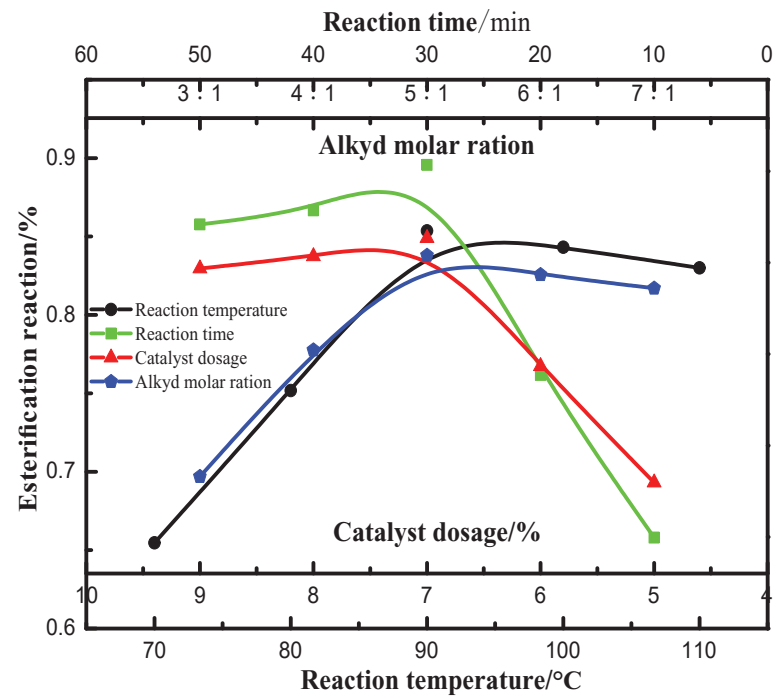

(d)

Figure 4: Effect of different factors on the conversion rate of stearate: (a) ethyl stearate, (b) propyl stearate, (c) butyl stearate, (d) amyl stearate.

Table 1: Optimum reaction conditions of the esters.

\begin{tabular}{lccccc}
\hline Material & $\begin{array}{c}\text { Reaction } \\
\text { temperature }\end{array}$ & $\begin{array}{c}\text { Reaction } \\
\text { time }\end{array}$ & $\begin{array}{c}\text { Amount } \\
\text { of catalyst } \\
\text { on yield }\end{array}$ & $\begin{array}{c}\text { Alkyd Esterification } \\
\text { molar } \\
\text { ratio }\end{array}$ & \\
\hline $\begin{array}{l}\text { Methyl } \\
\text { stearate }\end{array}$ & $65^{\circ} \mathrm{C}$ & $90 \mathrm{~min}$ & $7 \%$ & $30: 1$ & $97.79 \%$ \\
$\begin{array}{l}\text { Ethyl } \\
\text { stearate }\end{array}$ & $80^{\circ} \mathrm{C}$ & $240 \mathrm{~min}$ & $6 \%$ & $9: 1$ & $97.33 \%$ \\
$\begin{array}{l}\text { Propyl } \\
\text { stearate }\end{array}$ & $85^{\circ} \mathrm{C}$ & $210 \mathrm{~min}$ & $10 \%$ & $5: 1$ & $97.46 \%$ \\
$\begin{array}{l}\text { Butyl } \\
\text { stearate }\end{array}$ & $110^{\circ} \mathrm{C}$ & $200 \mathrm{~min}$ & $10 \%$ & $10: 1$ & $98.97 \%$ \\
$\begin{array}{l}\text { Amyl } \\
\text { stearate }\end{array}$ & $90^{\circ} \mathrm{C}$ & $30 \mathrm{~min}$ & $7 \%$ & $5: 1$ & $97.29 \%$ \\
\hline
\end{tabular}

the forward and reverse reactions, respectively; $r$ and $d$ are the molar ratios of the stearic acid ester and water, respectively.

As the alcohol is in excess, the reverse reaction can be considered as negligible. Thus:

$$
r_{A}=k C_{A}^{a} C_{B}^{b}
$$

Due to the excess alcohol, $k C_{B}^{b}$ can be approximated as a constant. Therefore, Eq. 4 can be transformed into:

$$
r_{A}=k C_{A}^{n}
$$

where $K=k C_{B}^{b}$. 
The initial concentration of stearic acid is $C_{A O}$ and yield of stearic acid ester is $\mathrm{X}$. The concentration of stearic acid in the reaction system at any time is $\mathrm{C}_{\mathrm{A} 0}$, therefore its concentration at any given time is $\mathrm{C}_{\mathrm{A}}=\mathrm{C}_{\mathrm{AO}}(1-\mathrm{X})$. Thus:

$$
\begin{aligned}
& r_{A}=-\frac{d C_{A}}{d t}=-\frac{d\left[C_{A 0}(1-X)\right]}{d t}=C_{A 0} \frac{d x}{d t}=k_{1} C_{A}^{n} \\
& \frac{d x}{d t}=\frac{k_{1}}{C_{A 0}}\left[C_{A 0}(1-X)\right]^{n}=k_{2}\left[C_{A 0}(1-X)\right]^{n}
\end{aligned}
$$

then:

$$
\frac{d X}{(1-X)^{n}}=\frac{K(n-1)}{C_{A 0}^{1-n}} d t
$$

Integrating both sides of Eq. 8 gives:

$$
(1-X)^{(1-n)}=\frac{K(n-1)}{C_{A O}^{1-n}} t+1
$$

At different values of $n$, the final formula will be different. Thus, the correlation coefficient will be different as well. Figure 5 shows that conversions rates for all esters were not linear, thus $n \neq 0$.

Correlation coefficient for different $n$ values can be calculated, and the maximum value of the correlation coefficient can be taken as the reaction order. The least squares method was used to obtain different $n$ values [21] using methyl stearate as an example (shown in Table 2).

At $n=2$, the correlation coefficient is the highest at all temperatures. Therefore, reaction order of the esterification reaction is 2 . The reaction orders of the other four esters were obtained in the same way (see Table 3).

\subsubsection{Activation energy determination}

Activation energy was determined using the Arrhenius equation which can be expressed as follows:

$$
k=A e^{-\frac{E_{a}}{R T}}
$$

where $\mathrm{k}$ is the reaction rate constant; $\mathrm{A}$ is the preexponential factor; $E_{a}(\mathrm{~kJ} / \mathrm{mol})$ is the activation energy; and $\mathrm{R}$ is the universal gas constant equal to $8.314 \mathrm{~J} /(\mathrm{mol} \cdot \mathrm{K})$.

By taking the logarithm of both sides, the following equation is obtained:

$$
\ln k=-\frac{E_{a}}{R T}+\ln A
$$

Since the relationship between $\ln \mathrm{k}$ and $1 / \mathrm{T}$ is linear, taking methyl stearate as an example, the data can be fitted in a straight line (as shown in Figure 6) with the correlation coefficient $\mathrm{R}^{2}=0.9600$.

The activation energy and pre-exponential factor calculated from the slope and the intercept of the line in Figure 5 were $30.3 \mathrm{~kJ} / \mathrm{mol}$ and $3.8709 \cdot 10^{4}$, respectively. With these parameters, kinetic model of the reaction can be expressed as follows:

$$
-\frac{d C A}{d t}=3.8709 \times 10^{4} e^{\frac{-30.300}{R T} C_{A}^{2}}
$$

The same method was used to obtain the correlation coefficient and kinetic model of ethyl stearate, propyl ester, butyl ester and amyl ester. The results are shown in Figure 7 and Table 3.

\subsection{IR characterization}

As shown in Figure 8, the absorption peaks at $2927 \mathrm{~cm}^{-1}$ and $2808 \mathrm{~cm}^{-1}$ corresponded to the $\mathrm{C}-\mathrm{H}$ stretching vibration of $-\mathrm{CH}_{3}$, and the $\mathrm{C}-\mathrm{H}$ asymmetric and symmetric stretching vibrations of $-\mathrm{CH}_{2}^{-}$, respectively. The peak at $1660 \mathrm{~cm}^{-1}$ is characteristic for the ester group. The peaks at $1488 \mathrm{~cm}^{-1}$ and $1388 \mathrm{~cm}^{-1}$ correspond to the vibrational stretching of CO [22]. Thus, the IR spectrum confirms the structure of methyl stearate.

Infrared spectra of ethyl-, propyl-, butyl- and amylstearate esters are shown in Figure 9.

\subsection{Measurement and analysis of low-temperature fluidity}

Low-temperature fluidity is an important criterion for evaluating the quality of biodiesel fuels. Evaluation indices such as cloud point, solidification point, cold filter plugging point and pour point are generally used to characterize the low-temperature fluidity [13]. Cloud point (CP) refers to the temperature at which the oil crystallizes and becomes cloudy. Solidification point (SP) refers to the temperature at which the oil no longer flows. Pour point (PP) refers to the point when the oil moves when the container is tilted. Temperature of cold filter plugging point (CFPP) reflects oil fluidity at low temperatures and 


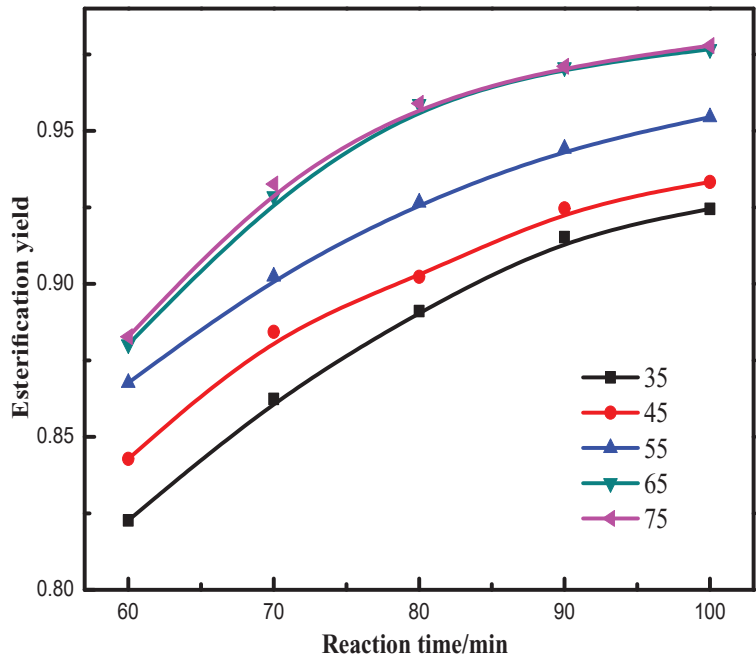

(a)

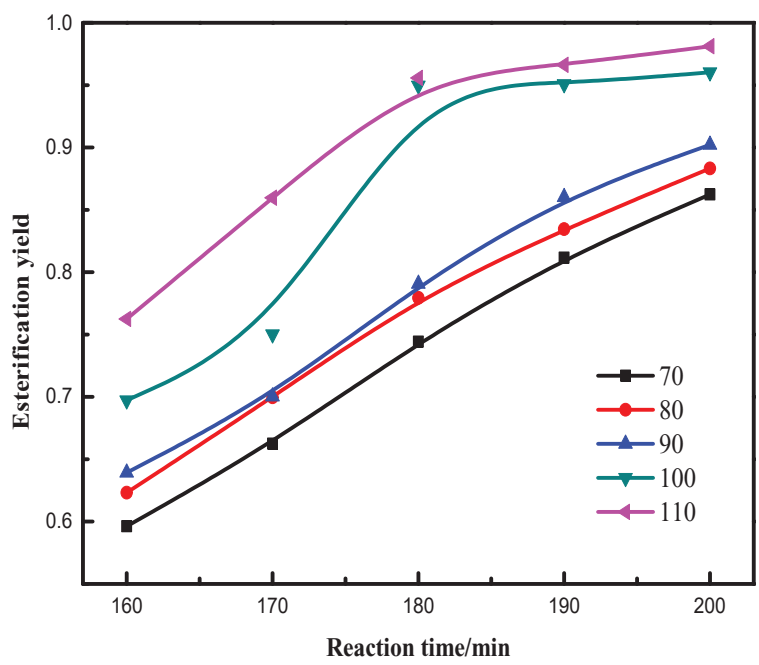

(c)

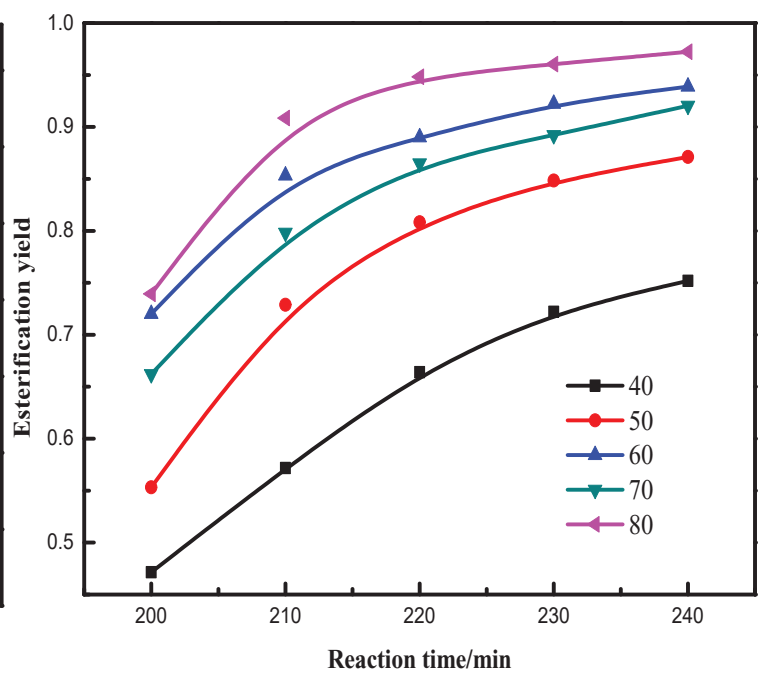

(b)

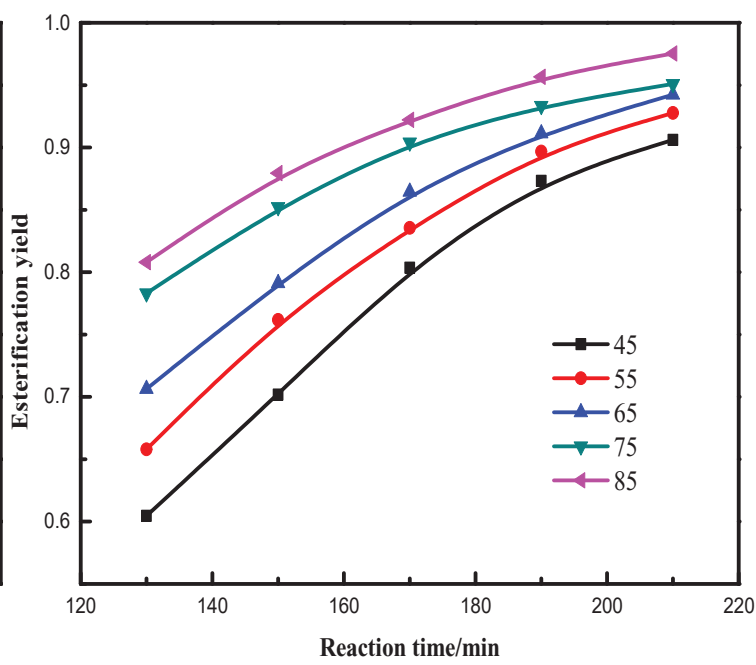

(d)

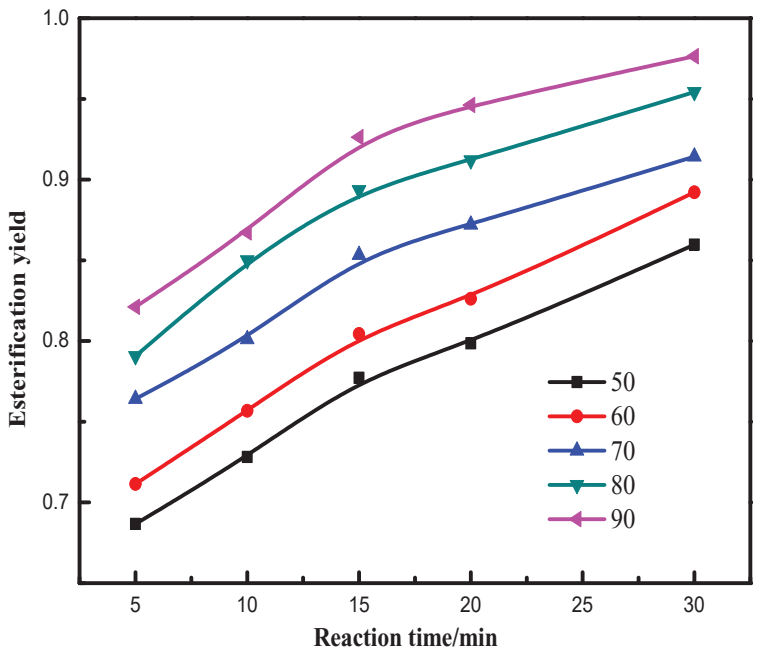

(e)

Figure 5: Rate of the esterification reaction of different stearate esters: (a) methyl stearate, (b) ethyl stearate, (c) propyl stearate, (d) butyl stearate, (e) amyl stearate. 
represents the maximum temperature at which oil cannot pass through the filter within $1 \mathrm{~min}$. The values of SP, CFPP and kinematic viscosity of methyl stearate, ethyl stearate, propyl stearate, butyl stearate and amyl stearate were analyzed, and the results are shown in Figure 10 [23].

It can be seen from Figure 10 that the SP and CFPP of the stearic acid esters gradually decreased as the

Table 2: Correlation coefficients of different reaction orders for methyl stearate.

\begin{tabular}{llll}
\hline Reaction temperature $\left({ }^{\circ} \mathrm{C}\right)$ & \multicolumn{1}{c}{$\boldsymbol{R}_{\mathbf{1}}^{2}$} & \multicolumn{1}{c}{$\boldsymbol{R}_{\mathbf{2}}^{2}$} & \multicolumn{1}{c}{$\boldsymbol{R}_{\mathbf{3}}^{\mathbf{2}}$} \\
\hline 45 & 0.9823 & 0.9923 & 0.9765 \\
55 & 0.9817 & 0.9918 & 0.9753 \\
65 & 0.9852 & 0.992 & 0.9519 \\
75 & 0.9730 & 0.9925 & 0.9447 \\
85 & 0.9791 & 0.9919 & 0.9272 \\
\hline
\end{tabular}

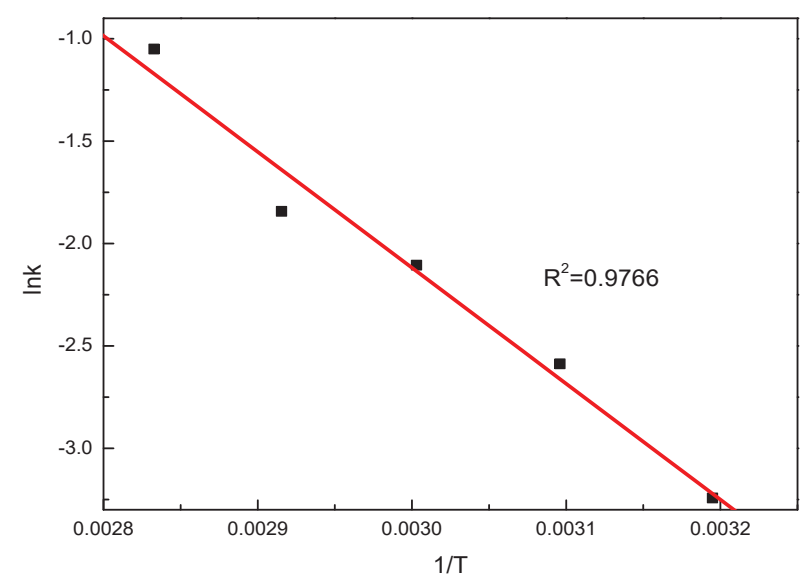

(a)

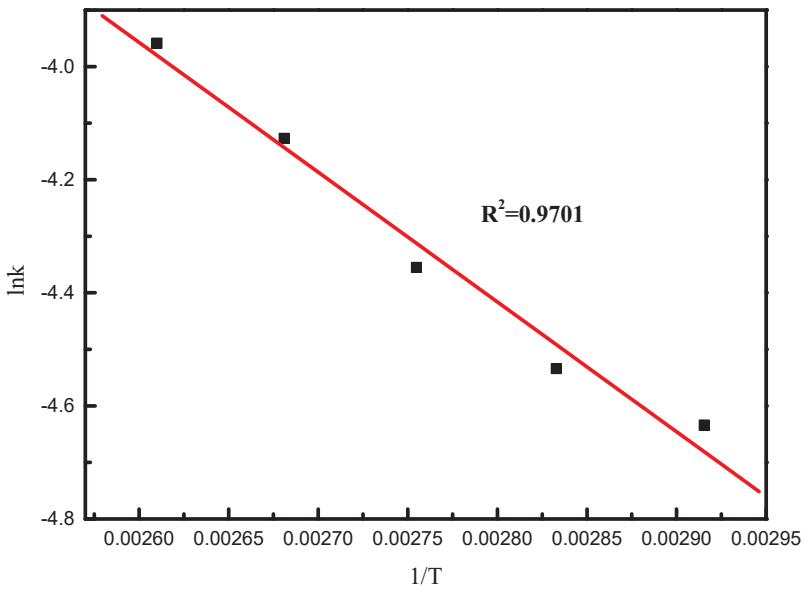

(c)

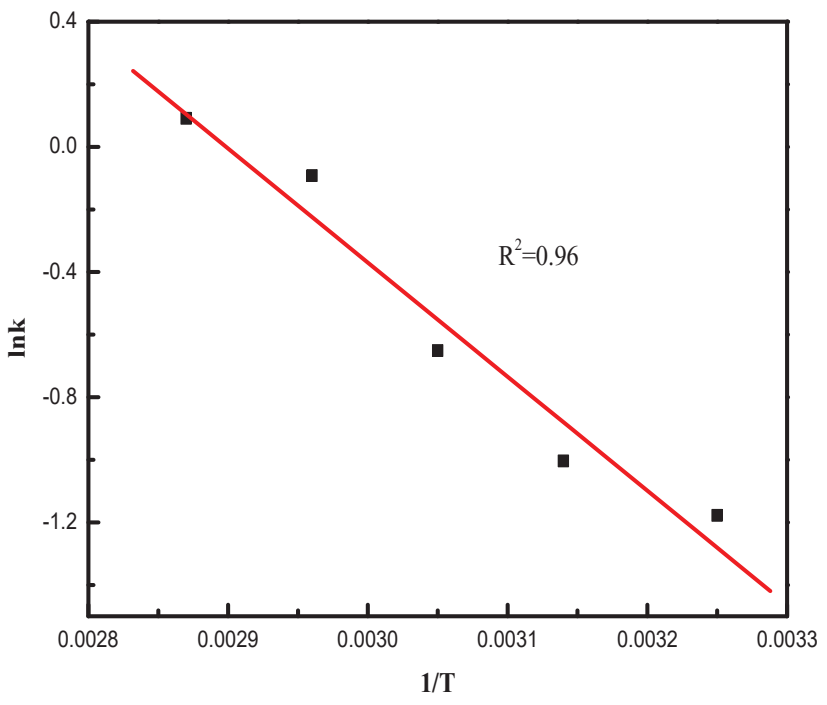

Figure 6: Relationship between Ink and $1 / T$ for the methyl stearate reaction.

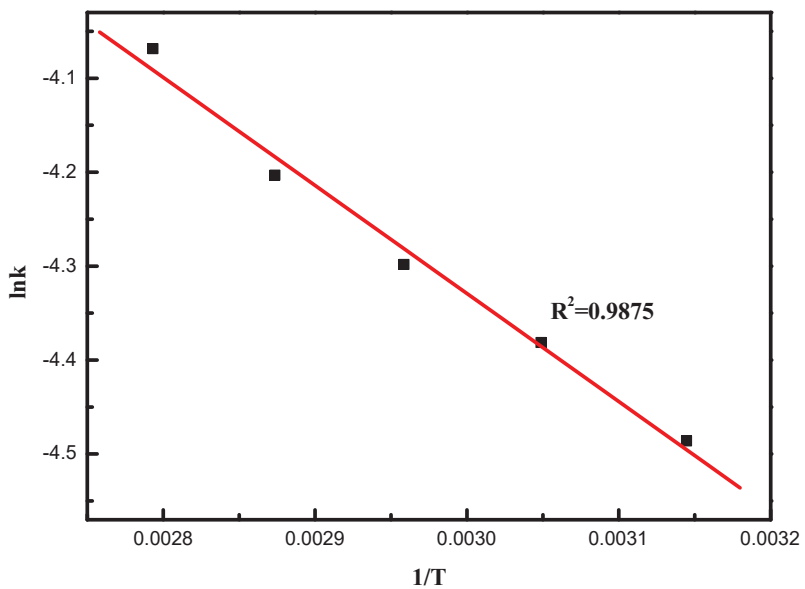

(b)

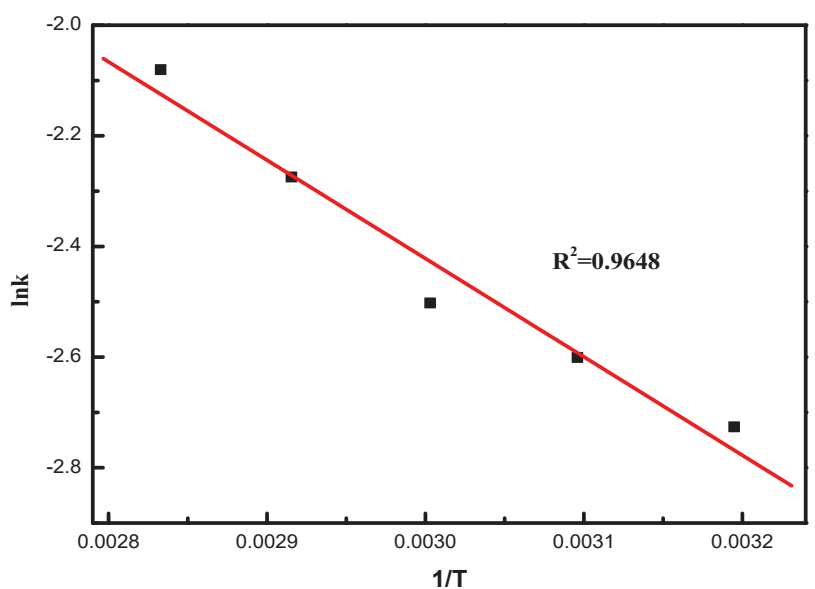

(d)

Figure 7: Relationship between Ink and 1/T for the esterification reactions: (a) ethyl stearate, (b) propyl stearate, (c) propyl stearate, (d) amyl stearate. 
Table 3: Correlation coefficients and kinetic models for esterification reaction with different alcohols.

\begin{tabular}{|c|c|c|c|}
\hline Material & $A$ factor & $\begin{array}{c}\text { Activation } \\
\text { energy }(\mathrm{KJ} / \mathrm{mol})\end{array}$ & Kinetic model \\
\hline $\begin{array}{l}\text { Methyl } \\
\text { stearate }\end{array}$ & 2 & 30.3 & $-\frac{d C A}{d t}=3.8709 \times 10^{4} e^{\frac{-30.3}{R T}} C_{A}^{2}$ \\
\hline $\begin{array}{l}\text { Ethyl } \\
\text { stearate }\end{array}$ & 2 & 47.078 & $-\frac{d C_{A}}{d t}=2.95 \times 10^{6} e^{\frac{-47.078}{R T}} C_{A}^{2}$ \\
\hline $\begin{array}{l}\text { Propyl } \\
\text { stearate }\end{array}$ & 1 & 11.539 & $-\frac{d C_{A}}{d t}=4.86 e^{\frac{-11.539}{R T}} C_{A}$ \\
\hline $\begin{array}{l}\text { Butyl } \\
\text { stearate }\end{array}$ & 1 & 19.085 & $-\frac{d C_{A}}{d t}=7.47 e^{\frac{-19.085}{R T}} C_{A}$ \\
\hline $\begin{array}{l}\text { Amyl } \\
\text { stearate }\end{array}$ & 1 & 14.778 & $-\frac{d C_{A}}{d t}=18.37 e^{\frac{-14.778}{R T}} C_{A}$ \\
\hline
\end{tabular}

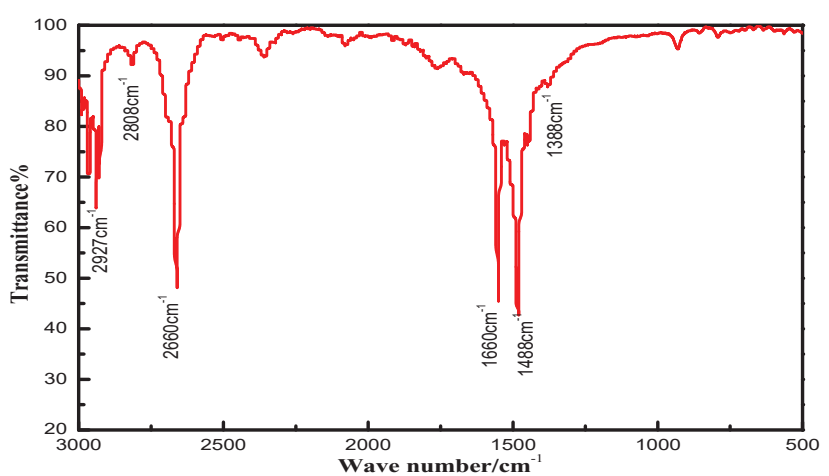

Figure 8: IR spectrum of methyl stearate.

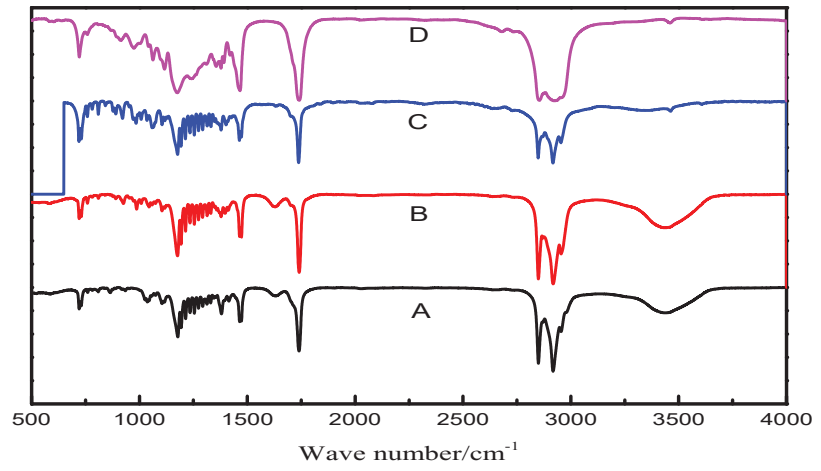

Figure 9: Infrared spectra of (A) ethyl, (B) propyl, (C), butyl and (D) amyl stearate esters.

carbon chain length of the esters increased. Amyl stearate showed the lowest values of SP and CFPP, i.e., 51.5\% and $40 \%$, respectively, which were lower than those of methyl stearate. Thus, longer carbon chains lowered the temperature of the flow as well as the kinematic viscosity. Kinematic viscosity of propyl stearate exceeded the

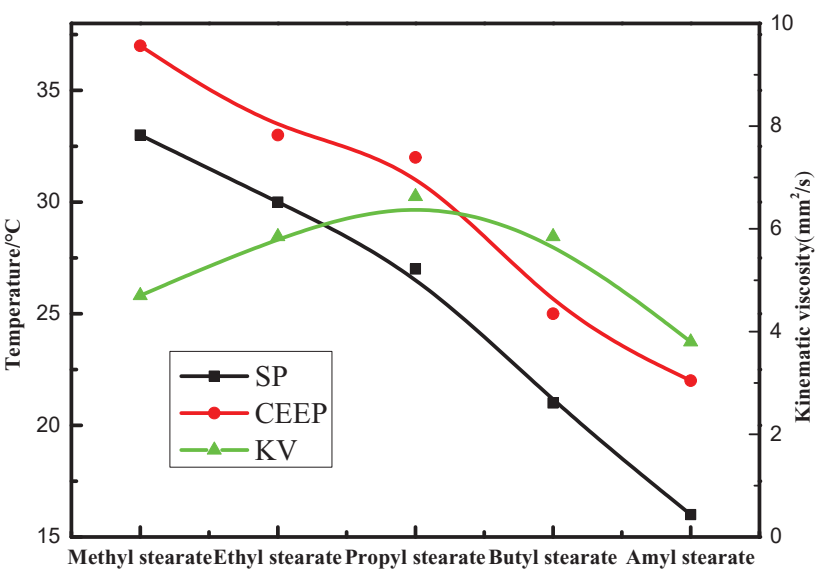

Figure 10: SP, CFPP and viscosity of the esters.

national standard, while the kinematic viscosity values of the other four esters were lower than the national standard of $6 \mathrm{~mm}^{2} / \mathrm{s}$.

\section{Conclusions}

(1) Effects of the reaction temperature, reaction time, amount of catalyst and molar ratios of alkyd on the esterification rate were analyzed. The optimal reaction conditions were determined for five different esters. The esterification rate reached $97 \%$ at the optimum conditions.

(2) The final products were characterized by infrared analysis. Based on the functional groups in the infrared spectra, the products were confirmed as methyl stearate, ethyl stearate, propyl stearate, butyl stearate and amyl stearate.

(3) The kinetic analysis of the branched stearic acid ester was performed by the integral method to obtain the reaction series, activation energy, and kinetic model.

(4) Condensation point, cold filter plugging point and kinematic viscosity of all five esters were determined. The condensation and cold filter plugging points gradually decreased with the increase in length of the carbon chain. Thus, by increasing the carbon chain length, it would be possible to optimize the low temperature flow performance. The viscosity of the esters (with the exception of propyl stearate) was lower than the national standard.

Acknowledgments: This work was funded by the National Natural Science Foundation of China (51766007), National Natural Science Foundation of Yunnan (2018FB092), and NSFC-Yunnan Joint Fund Project (U1602272). 


\section{References}

[1] Luo Y.Q., Wang X., Yuan X.G., Energy and carbon balances in microalgae biodiesel. J. Tsinghua Univ.-Nat. Sci. Ed., 2018, (58)03, 324-329.

[2] Qi J.L., Gao Y.J., Ding H., Ye W., Liu D., Gui J.Z., Recent Advances in Preparation of Biodiesel Using Ionic Liquids as Catalysts. Chem. Ind. Eng., 2017, 34(5), 25-28.

[3] Deng Z.Q., Zhong X.F., Liu H.F., Wang X.F., Hu B., Effect of Biodiesel/DMF Blended Fuel on Low Temperature Combustion in a Diesel Engine. J. Combust. Sci. Technol., 2017, 23(2), 104-106.

[4] Zhou C., Wang F., He W.Z., Li G.G., Research development in purification of glycerol produced from the homogeneous base catalyzed biodiesel. Prog. Chem., 2016, 35(2), 463-465.

[5] Yang K.K., Li X.X., Li J.G., Wang J.S., Wang X.B., Experiment on Spray Characteristics of Alcohol and Biodiesel Blends. T Csice., 2016, 34(3), 260-263.

[6] Qu L., Study on the Formation and Characteristics of Particles with Biodiesel Blend Fuels in the Exhaust Gas Atmosphere. Jiangsu University, 2017.

[7] Ma X.R., Qin J.L., Wu H.Z., Xu Y.C., Xu Y., Cao Y., Qiao D.R., et al., Preparation of a $\mathrm{Fe}_{3} \mathrm{O}_{4} @ \mathrm{SiO}_{2}-\mathrm{CHO}$ carrier and immobilized lipase as a recyclable catalyst for biodiesel production. Chin. J. Appl. Environ. Biol., 2017, 23(2), 0256-0263.

[8] Xue Y., Study on the cold flow properties improvement of biodiesel and is depression mechanism under low temperature. Shanghai Institute of Technology, 2017.

[9] Shen J.X., Li F.S., Wang H.G., Shen Y.C., Liu Z.W., Zhang X.H., Compound effects of antioxidants and pour point depressants on biodiesel performance. China Oils and Fats, 2018, (43)03, 105-106.

[10] Parsaeimehr A., Sun Z.L., Dou X., Chen Y.F., Simultaneous improvement in production of microalgal biodiesel and highvalue alpha-linolenic acid by a single regulator acetylcholine. Biotechnol. Biofuels, 2015, 8, 1-10.

[11] Liang Z.S., Li F.S., Bao G.R., Zhang X.H., Wang C.Z., Optimization and evaluation of pour point depressant on low temperature fluidity property of rapeseed oil biodiesel.China Oils and Fats, 2016, (41)9, 69-73.
[12] Hu J.M., Chem X., Yuan H., Lai Y.B., Zhang Y.Q., Shu J.F., et al., Study on cold flow properties of waste cooking methyl ester. Renew. Energ. Res., 2015, (33)03, 457-461.

[13] Dan S., Choudhury H., Sarkar H., Gorain B., Barik A., Ghosh B., et al., A randomized two-way crossover comparative pharmacokinetic study of two different tablet formulations containing ilaprazole in healthy human Indian volunteers. Arch. Med. Heal. Sci., 2014, 2, 160-164.

[14] Huang D.S., Lv P.G., Cheng Y.F., Pan H., Luo W., Yang L.M., et al., Improving the cold flow properties of palm oil biodiesel. Act. Energ. Sin., 2014, 35(3), 391-395.

[15] Cai L.L., Yuan Y.N., Chen X., Lai Y.B., Chen L., Cold flow properties and Crystallization of Palm oil biodiesel. Petrkchem Techno., 2015, 44(3), 358-361.

[16] Makarevičienė V., Kazancev K., Kazanceva J., Possibilities for improving the cold flow properties of biodiesel fuel by blending with butanol. Renew. Energ., 2015, 75, 805-807.

[17] Ranjan A., Dawn S.S., Jayaprabakar J., Nirmala N., Saikiran K., Sriram S.S., Experimental investigation on effect of $\mathrm{MgO}$ nanoparticles on cold flow properties, performance, emission and combustion characteristics of waste cooking oil biodiesel. Fuel, 2018, 220, 780-791.

[18] Joshi H., Moser B.R., Toler J., Smith W.F., Walker F., Ethyl levulinate: A potential bio-based diluent for biodiesel which improves cold flow properties. Biomass and Bioenergy, 2011, 35(7), 3262-3266.

[19] Turns S.R., An Introduction to Combustion concepts and Applications. Tsinghua University Press, 2009.

[20] Ge H.C., Zhu M.G., An efficient method for solving reaction orders with Excel software. Lab. Sci., 2013, 16(1), 108-109.

[21] Li F.S., Wang Z., Bao G.R., Wang H., Li M., Li Y.Z., et al., Catalytic preparation and dynamics analysis and cold flow property for oleic acid isopropyl ester. Act. Energ. Sin., 2014, 35(12), 2535-2537.

[22] Yang Y.J., Han Q.W., Yang Y.F., Study on synthesis of methyl stearate. Chem. Res., 2012, 23(5), 17-19.

[23] Mia S., Ohno M., Relation between low temperature fluidity and sound velocity of lubricating oil. Tribol. Int., 2015, 5(6), 201-204. 